\title{
AFRODESCENDÊNCIA E METODOLOGIAS INVENTIVAS PARA IMPLEMENTAÇÃO DA LEI N. 10.639/03 NA ESCOLA: A CRIAÇÃO DE JOVENS DA PEDAGOGIA
}

\author{
AFRODESCENDENCIA Y METODOLOGÍAS INVENTIVAS PARA LA APLICACIÓN \\ DE LA LEY N 10.639/03 EN LA ESCUELA: LA CREACIÓN DE JÓVENES DE LA \\ PEDAGOGÍA
}

\begin{abstract}
AFRODESCENDENCE AND INVENTIVE METHODOLOGIES FOR IMPLEMENTING LAW N 10.639/03 IN SCHOOL: THE CREATION OF YOUNG PEOPLE IN PEDAGOGY
\end{abstract}

\author{
Shara Jane Holanda Costa ADAD ${ }^{1}$ \\ Thaysa Tâmara Maciel dos SANTOS ${ }^{2}$ \\ Maria do Socorro Borges da SILVA ${ }^{3}$
}

RESUMO: Este artigo problematiza a afrodescendência na escola, com graduandos/as da formação inicial em Pedagogia, propiciando a criação de metodologias sensíveis para a discussão e implementação da Lei $\mathrm{n}^{\mathrm{o}}$ 10.639/03, reconhecendo e valorizando a cultura de crianças, adolescentes e jovens negras, por meio das suas escritas de si e de marcadores afrorreferenciados, reconhecendo-os e integrando-os de modo participativo na escola. Utiliza o método híbrido do Círculo de Cultura Sociopoético, com destaque para a potência do uso da arte e do corpo na criação coletiva do conhecimento e das seguintes metodologias: 1 . Autorreconhecimento que mostra como problema o trabalho individual e solitário do/a professor/a e a necessidade coletiva e comunitária de uma ética ubuntu; e 2. hashtag Angú da Luta (\#angudaluta) que destaca a luta coletiva e o amor nos enfrentamentos do racismo e nos modos de sentir-pensar-agir a existência viva infanto-juvenil, como contribuição para a implementação da Lei no espaço escolar.

PALAVRAS-CHAVE: Afrodescendência. Escola. Marcadores Afrorreferenciados. Metodologias inventivas. Lei 10.639/03. Formação Inicial.

RESUMEN: Este paper problematiza a los afrodescendientes en la escuela, con estudiantes de la formación inicial en Pedagogía, posibilitando la creación de metodologías sensibles para la discusión e implementación de la Ley $N^{\circ} 10.639 / 03$, reconociendo y valorando la cultura de la niñez, adolescencia y juventud negras a través de sus escritos de sí mismo y marcadores afrorreferenciados, reconociéndolos e integrándolos de manera participativa en la escuela. Utiliza el método híbrido del Círculo de Cultura Sociopoética, con énfasis en el poder del uso del arte y el cuerpo en la creación colectiva de conocimiento y las siguientes metodologías: 1. Autorreconocimiento que muestra el trabajo individual y solitario del el individuo como profesor problemático y la necesidad colectiva y comunitaria de una ética

${ }^{1}$ Universidade Federal do Piauí (UFPI), Teresina - PI - Brasil. Professora Associada no Departamento de Fundamentos da Educação - DEFE/CCE. Doutorado em Educação Brasileira (UFC). ORCID: https://orcid.org/0000-0001-7711-6325.E-mail: shara_pi@hotmail.com

${ }^{2}$ Universidade Federal do Piauí (UFPI), Teresina - PI - Brasil. Mestranda no Programa de Pós-Graduação em Educação da UFPI. ORCID: https://orcid.org/0000-0001-5852-7946. E-mail: thaysamix2009@hotmail.com

${ }^{3}$ Universidade Federal do Piauí (UFPI), Teresina - PI - Brasil. Professora no Departamento de Fundamentos da Educação - DEFE/CCE. Doutorado em Educação (UFPI). ORCID: http://orcid.org/0000-0003-1502-1341. Email: msocorrobs@ufpi.edu.br

RIAEE - Revista Ibero-Americana de Estudos em Educação, Araraquara, v. 16, n. 2, p. 682-702, abr./jun. 2021. e-ISSN: 1982-5587 
ubuntu; y 2. hashtag Angú da Luta (\#angudaluta) que resalta la lucha colectiva y el amor frente al racismo y en las formas de sentir-pensar-actuar la existencia viva de niños, niñas y adolescentes, como contribución a la implementación de la Derecho en el espacio escolar.

PALABRAS CLAVE: Afrodescendencia. Escuela. Marcadores Afrorreferenciados. Metodologías inventivas. Ley 10.639/03. Formación Inicial.

ABSTRACT: This article problematizes Afro-descendants at school, with undergraduate students from initial training in Pedagogy, enabling the creation of sensitive methodologies for the discussion and implementation of Law No. 10,639/03, recognizing and valuing the culture of black children, black adolescents and young black people, through his writings of himself/herself and african-referrenced markers, recognizing and integrating them in a participatory way in school. It uses the hybrid method of the Sociopoetic Culture Circle, with emphasis on the power of using art and the body in the collective creation of knowledge and the following methodologies: 1. Self-recognition that shows the problema as the individual and solitary work of the teacher and the collective and community need for ubuntu ethics; and 2. hashtag Angú da Luta (\#angudaluta) that highlights collective struggle and love in the face of racism and in the ways of feeling-thinking-acting the childhood-Youth existence as a contribution to the implementation of the Law in the school space.

KEYWORDS: Afrodescendence. School. Inventive methodologies. African-referrenced Markers. Law 10.639/03. Initial Education.

\section{Introdução}

Este artigo integra as pesquisas desenvolvidas no projeto Educação, Corpo e Movimento: agenciamentos de afectos $^{4}$, processos de criação e de resistências nas práticas educativas com/entre crianças e jovens, como produção de outros modos de educar na contemporaneidade, vinculado à linha Educação, Diversidade/diferença e inclusão, do Programa de Pós-Graduação em Educação - PPGEd, da Universidade Federal do Piauí UFPI, do Núcleo de estudos e pesquisas "Educação, gênero e cidadania" - NEPEGECI e do Observatório das Juventudes e Violências na Escola - OBJUVE. Dentre as questões, as étnico-raciais nos interessam, sobretudo, por envolver os direitos das crianças, adolescentes e jovens periféricos, sujeitos com os quais os futuros profissionais da educação vão atuar, especialmente, na escola pública da Educação Básica.

O percurso deste trabalho se inicia com o problema de ser quem se é, presente em uma das pesquisas desenvolvidas com jovens futuros pedagogos e realizadas entre 2015 e 2017 .

\footnotetext{
${ }^{4}$ Tomamos de empréstimo a percepção de Deleuze e Guattari (1997, p. 79, grifos dos autores) acerca dos afectos: "[...] o sentimento implica uma avaliação de matéria e de suas resistências, um sentido de forma e de seus desenvolvimentos, uma economia da força e de seus deslocamentos, toda uma gravidade. Mas o regime da máquina de guerra é antes dos afectos, que só remetem ao móvel em si mesmo, a velocidades [...], o afecto é descarga rápida de emoção, o revide, ao passo que o sentimento é uma emoção sempre deslocada, retardada, resistente".
} 
Naquelas trajetórias, os discentes trouxeram como discussão, as dificuldades de ser quem são na universidade e que o Curso de Pedagogia poderia veicular o pensar crítico a respeito da questão racial e da contribuição da Lei $n^{\circ} 10.639 / 03$ (BRASIL, 2003), em todas as matérias sem se restringir às disciplinas optativas. A Lei em questão trata da obrigatoriedade do Ensino da História e da Cultura Afro-brasileira e Africana nos currículos das escolas de Educação Básica e determina que:

Art. 26-A. Nos estabelecimentos de ensino fundamental e médio, oficiais e particulares, torna-se obrigatório o ensino sobre História e Cultura AfroBrasileira. $\S 1^{\circ}$ - O Conteúdo programático a que se refere o caput deste artigo incluirá o estudo da História da África e dos africanos, a luta dos negros no Brasil, a cultura negra brasileira e o negro da formação da sociedade nacional, resgatando a contribuição do povo negro nas áreas sociais, econômica e política, pertinentes à História do Brasil. $\S 2^{\circ}$ Os conteúdos referentes à História e Cultura Afro-Brasileira serão ministrados no âmbito de todo o currículo escolar, em especial nas áreas de Educação Artística e de Literatura e de História Brasileiras. Art. 79-B. O calendário escolar incluirá o dia 20 de novembro como o 'Dia Nacional da Consciência Negra' (BRASIL, 2003, p. 01).

Neste caso, ressalta a importância da história da África e da cultura afro na formação da sociedade brasileira, fruto da luta empreendida pelo movimento social negro, que buscou quebrar com as representações atribuídas à África e seus descendentes, com o intuito de questionar o currículo eurocêntrico presente nas escolas e universidades, historicamente responsável pelo esquecimento da potencialidade de infanto-juvenis na escola, fazendo com que, inclusive, não se identifiquem com o que estudam e com aquele espaço.

Como pesquisadoras do social, nos sentimos motivadas a estudar sobre a Lei n. 10. 639/03 (BRASIL, 2003), problematizando a afrodescendência na escola ${ }^{5}$ com discentes do Curso de Pedagogia, levando-os a criar práticas educativas que considerassem as diversidades étnico-raciais desde a Educação Superior à Educação Básica. Neste caso, também, o intuito foi propiciar a criação de metodologias inventivas. Escolhemos graduandos que estivessem nos estágios docentes e, que, a partir de suas experiências formativas na academia, pensassem este problema como emergente, pois continuamente os afrodescendentes enfrentam isso na

${ }^{5}$ Conforme Boakari (2015, p. 22), "o termo afrodescendente tem carga positiva de reafirmação de origem, identidade e história, que acredita na origem africana de todos os seres humanos, e configura-se no mais apropriado, pois, permite acesso a nossa própria história afrodescendente". Petit (2015, p. 171) traz como nosso "pertencimento afro, que é situar-se dentro da ancestralidade africana, saber que se faz parte de uma linhagem que, para além de biológica, é de parentesco cultural". Em vista disso, "não estamos mais nos referindo ao africano como distante, na terceira pessoa, e sim como parte do nosso convívio diário, e, é isso que traz sentimento de pertencimento" (PETIT, 2015, p.176).

RIAEE - Revista Ibero-Americana de Estudos em Educação, Araraquara, v. 16, n. 2, p. 682-702, abr./jun. 2021. e-ISSN: 1982-5587 
escola - e representam a demanda de uma infância e juventude periféricas, marcadas pela exclusão de classe, de raça/etnia, de lugar dentre outras (SILVA; ADAD; SILVA, 2020).

Este movimento nos permitiu entender que iniciativas na universidade são fundamentais para atender as Políticas das Relações Étnicos-Raciais, pois quanto maior for o número e a qualidade dos estudos, maior o alcance: desde a formação inicial de professores/as à inserção desta problemática nos currículos escolares, de modo a modificar as práticas educativas discriminatórias, fomentadoras do racismo nas situações de preconceitos, de estigmas, de desvalorização e mesmo de extermínio das vidas afrodescendentes no Brasil.

Acreditamos que as universidades públicas podem ser um espaço de acolhimento aos diferentes saberes, reconhecendo a cultura e história afrodescendente, propiciando rupturas no currículo eurocêntrico herdado e que é ensinado nas escolas e nas universidades. A formação inicial propicia encontros com os saberes pedagógicos e experienciais das pessoas, com outras culturas e com as possibilidades de criação, nos permitindo compreender que implementar a Lei $n^{0}$ 10.639/03 (BRASIL, 2003) no sistema educacional passa por uma formação sensível, diferenciada, crítica, oportunizando aos/as futuros/as pedagogos/as pensar, problematizar e questionar as estruturas racistas - (re)produtoras de verdade única sobre os Afrodescendentes e sua história.

Diante do exposto, o problema de pesquisa que nos mobilizou foi: Como problematizar a afrodescendência na escola e criar com graduandos/as dispositivos metodológicos sensíveis e inventivos para a discussão e implementação da Lei n. 10.639/03 (BRASIL, 2003), reconhecendo e valorizando as culturas de crianças, adolescentes e jovens afrodescendentes da Educação Básica? De modo específico, com a atitude de escutar e aprender com os/as graduandos/as de Pedagogia da UFPI, os nossos propósitos foram o de favorecer a produção dos problemas que mobilizavam os jovens graduandos do Curso de Pedagogia sobre o tema em questão, pensando a inclusão da cultura de crianças e jovens afrodescendentes; descrever os dispositivos metodológicos sensíveis e inventivos elaborados pelos referidos discentes e, por fim, identificar modos de pensar afrorreferenciado ${ }^{6}$ e de educar tendo em vista a implementação da referida Lei na escola. Para este artigo, descreveremos o processo metodológico da pesquisa e apresentaremos alguns dos resultados alcançados.

6 “O pensamento afrorreferenciado é delineado, trançado, bordado por nossas experiências, nosso viver, nossos modos de construção do cotidiano, do aprender / ensinar. Do ser / fazer. Para além da geografia física, são as geografias dos saberes transversalizados pelas vivências, pela territorialidade.” (MACHADO, 2019, p. 166). 


\title{
Círculo de Cultura Sociopoético na produção coletiva de conhecimento
}

\author{
A pesquisa foi realizada por meio do Círculo de Cultura Sociopoético (CCS). O CCS é
} um conhecimento híbrido entre o Círculo de Cultura Freireano e os princípios da sociopoética ${ }^{7}$ :

\begin{abstract}
Nos anos 60, a experiência de Paulo Freire com os círculos de cultura marcou profundamente a construção coletiva do conhecimento no campo da Educação Popular, por questionar os pilares da educação da sua época, notadamente a relação educador-educando. Este artigo pretende discutir como, no âmbito de uma disciplina da pós-graduação da Faculdade de Educação da Universidade Federal do Ceará, um grupo de pessoas se inspirou nessas ideias de Freire para possibilitar que acadêmicos e não acadêmicos construíssem conhecimento juntos. No entanto, ao se apropriar do círculo de cultura, decidiu-se recriá-lo com adaptações, pois mesclamos essa proposta de construção coletiva do conhecimento com o método da sociopoética. Do ideário freireano, aproveitamos as reflexões sobre a necessidade de construir conhecimento com grupos heterogêneos, bem como de se instituir relações não hierárquicas entre educadores e educandos. Enquanto da sociopoética, enfatizamos o princípio de produzir conhecimentos com o corpo todo através de técnicas artísticas (SOARES, 2019, p. 60).
\end{abstract}

Ressaltamos que a escolha dos princípios de considerar o corpo todo e a criação de dispositivos artísticos na produção coletiva do conhecimento tem o propósito:

[...] autoformador de construção coletiva do conhecimento e de aproximação e interação entre a comunidade e a universidade. Os Círculos de Cultura Sociopoéticos são estruturados no formato de oficinas e nele recorremos a diferentes linguagens artísticas com o objetivo de provocar a escuta sensível, e investigar a imaginação e facilitar a produção de múltiplas ideias e os conceitos acerca dos temas geradores estudados (ADAD; SILVA, 2013, p. 25).

O CCS aproxima vários grupos de resistências, ao permitir a construção do conhecimento em grupo, além de favorecer um encontro mais autêntico, gerar um espaço de convivência essencial à quebra de preconceitos e hierárquicos que acontece no processo de construção de conhecimento, pois:

\footnotetext{
${ }^{7} \mathrm{O}$ reconhecimento do corpo como fonte do conhecimento; a valorização das culturas dominadas, de resistência e das categorias que as mesmas produzem; o fato de tornar os sujeitos pesquisador corresponsáveis pelos conhecimentos produzidos enquanto copesquisadores; a potencialização da criatividade de tipo artístico no aprender, no conhecer e no pesquisar; a busca do sentido espiritual, humano, das formas e dos conteúdos no processo de construção dos saberes (ADAD, 2018; GAUTHIER; ADAD, 2020).
} 
Todo CC Sociopoético começa com uma dinâmica de construção de conhecimento preparada pelas facilitadoras. Cada um desses facilitadores propõem uma técnica ou linguagem artística diferenciada que será o veículo para a produção de conceitos acerca do tema gerador. Assim, no mesmo CC Sociopoético podem ser criados, por exemplo, mímicas, pinturas, músicas, cordéis, dança e esculturas em argila. Apresentadas as diferentes possibilidades artísticas os participantes escolhem a técnica que mais the chama atenção e assim são formados os subgrupos. Feitas a apresentação das pessoas no subgrupo, o mesmo acolhe o relator que ajuda a registrar as ideias de seus participantes que se engajam então numa conversa sobre o tema gerador. A partir do que foi conversado no subgrupo é elaborado a produção, sempre de maneira não diretiva, segundo os sentimentos e desejos expressos por todos. Todos são convidados pelo facilitador a contribuírem (sem discriminação de classe, categoria profissional, faixa etária, etc.) na produção artística e coletiva, linguagem para a qual são trazidas as reflexões dos participantes acerca do tema gerador. Uma vez pronta às produções artísticas, cada subgrupo as socializa apresentado a sua obra particular para o conjunto do grupo CC. No final, todos os participantes são chamados a avaliarem o encontro e o que propiciou em termo de sensações e aprendizagens (PETIT, 2019, p. 46).

Outro ponto a ser ressaltado, no CCS, é que o facilitador pode reinventá-lo conforme as mudanças no caminho, mantendo a perspectiva da criação por meio de técnicas artísticas. No nosso caso, inserimos as escritas de si que entendemos como exercício pessoal praticado por si e para si - relatar não por causa da importância de uma atividade, mas pela qualidade de um modo de ser (FOUCAULT, 1992). Neste caso, as escritas de si foram importantes para que selecionássemos modos de ser afrodescendentes presentes nas histórias de cada um/a, conforme dispostos nos fundamentos da Pretagogia (PETIT; ALVES, 2015). Uma vez selecionados, estes marcadores das africanidades compuseram o dispositivo para elaboração das metodologias pelos discentes.

A metodologia com o CCS aconteceu em dois momentos: o primeiro, de delimitação dos critérios para a escolha dos discentes em formação inicial no Curso de Pedagogia, da elaboração das técnicas a serem utilizadas nas oficinas e da formação do grupo-pesquisador na oficina de negociação da pesquisa; o segundo, trata-se da execução da oficina de produção dos dados no CCS para a construção do conhecimento coletivo acerca do referido tema e a elaboração de metodologias sensíveis e inventivas para discussão da Lei $\mathrm{n}^{\mathrm{o}}$ 10.63903 (BRASIL, 2003).

A pesquisa se iniciou com a negociação, momento de instituição do grupo-pesquisador formado por nós, as facilitadoras, e por 12 copesquisadores graduandos/as do Curso de Pedagogia da UFPI, de diferentes períodos que estavam atuando na Educação Básica, no estágio docência, e que demonstraram interesse em fazer parte da pesquisa com a citada temática. O convite destacou a importância de cada um/a enquanto corresponsável, coletivo e 
cocriador/a de conhecimento, em um "processo de aprendizagem, não apenas de técnicas artísticas, mas de aprendizagem inventiva, no sentido de que ali tem lugar, processos de invenção de si e do mundo." (KASTRUP; BARROS, 2015, p. 76).

No tópico a seguir, apresentaremos a experiência construída com os/as graduandos/as de Pedagogia com o CCS desde a oficina de negociação à produção dos dados.

\section{Primeiros movimentos do Círculo de Cultura Sociopoético}

A oficina de negociação com o grupo-pesquisador foi dedicada para os graduandos/as tomarem ciência da problemática que seria investigada. Para isso, fizemos uma roda de conversa sobre a Lei $n^{\circ} 10.639 / 03$ (BRASIL, 2003) e a temática da Afrodescendência na escola. Os copesquisadores, de algum modo, participaram falando o que sabiam sobre a Lei e o tema em questão e mostraram-se bem entusiasmados com a proposta da pesquisa.

A exemplo do que ocorre na Sociopoética, o CCS também começa com o relaxamento. Para este momento inicial, fizemos uma viagem pela imaginação com o intuito de transformar para conhecer, ao criar dispositivos que permitiram ao corpo sair das zonas confortáveis e entrar na associação, na acoplagem de sentidos ao nosso corpo, no êxtase, na poesia, no desprendimento, ao entrarmos na imaginação, nas histórias, no pensamento, nas palavras, na relação com os outros. Sentir, de diferentes modos, o corpo, percebendo-o no espaço, imergindo na proposta.

A viagem imaginária propiciou aos/as graduandos/as a produção de Escritas de $\mathrm{Si}$, a partir de diferentes imagens, sensações e emoções de momentos, lugares e pessoas que falavam de sua história de vida na relação com o tema proposto. Para a produção plástica da viagem, entregamos aos copesquisadores um espelho com a seguinte provocação: o que tem de afrodescendente em mim e na minha história? Solicitamos que eles olhassem para si e percebessem as marcas que esse corpo expressava. Para a produção das escritas de si disponibilizamos: massinha de modelar, giz de cera, pincéis e papel canson.

Por fim, nos despedimos com um lanche e pedimos como tarefa para a próxima oficina, que eles trouxessem objetos significativos, que fizessem relação com a sua escrita de si, a sua narrativa Afrodescendente que havia sido construída.

Para o próximo encontro, organizamos o processo de produção dos dados, iniciando pela transcrição dos relatos produzidos com a técnica das Escritas de si. Em seguida, elaboramos o plano e selecionamos os materiais plásticos necessários para a composição do 
dispositivo da próxima oficina. Foi uma semana intensa de preparação para o momento de produção das metodologias no CCS pelo grupo-pesquisador!

\section{Outros movimentos do Círculo de Cultura Sociopoético: os problemas e as metodologias inventivas}

O encontro para realização do CCS aconteceu na sala de Dança do Centro de Ciências da Educação de qual instituição? À medida que cada um chegava, pedíamos que entrassem, tirassem os sapatos, sentassem no chão em forma de roda, vivendo a circularidade dos afetos, de modo a sentir o chão da pesquisa. Em seguida, foram direcionados para viver ativamente o corpo, realizando vários alongamentos corporais, preparando o corpo para o momento do relaxamento. Fizemos procedimentos de respiração, pedindo que eles liberassem toda a energia que estava presa no corpo com movimentos com as mãos, os pés, pernas, costas, pescoço e cabeça, ou seja, com o corpo todo. Daquele momento, é possível observar o quanto alguns copesquisadores sentiram dificuldade de realizar os alongamentos e movimentos que envolviam equilíbrio e concentração, mostrando o corpo enrijecido, precisando de leveza.

Em seguida, solicitamos que os copesquisadores habitassem todos os espaços da sala com diferentes intensidades. De forma leve, enchendo o pulmão de ar e soltando-o pela boca, olhando o seu corpo, os detalhes, andando rápido, desviando dos obstáculos. Assim, os movimentos tornavam-se cada vez mais intensos, até aos poucos irem desacelerando os passos. Nesse momento, solicitamos que os/as copesquisadores parassem e olhassem para a pessoa mais próxima como um espelho. A brincadeira consistia no seguinte: combinávamos quem seria o espelho e quem seria a imagem, o espelho repetia os detalhados movimentos realizados pela imagem. Depois, eles inverteram os papéis, a pessoa que tinha sido o espelho, agora, assumia-se como imagem e, assim, foi feito.

Posteriormente, nos reunimos e fizemos uma roda dançante. Cada um se direcionava até o centro da roda, apresentando-se com o nome e dançando ao seu modo. Foi um momento bem prazeroso de ativação do nosso corpo! Depois, fizemos duplas dançantes com as pessoas que estavam do lado. Durante a realização dos movimentos de dança solicitamos que os/as copesquisadores fechassem os olhos para sentirem o movimento de seu corpo.

Esse momento de dançar em grupo foi inspirado em uma experiência que tinha como base os princípios da Pretagogia, protagonizada pela professora Dra. Sandra Petit, que nos permitiu despertar sentimentos de pertencimento e espiritualidade afrorreferenciadas. $\mathrm{O}$ dançar de forma comunitária é um momento de reconectar-se com a sua ancestralidade, envolve um sentimento de celebração, agradecimento e iniciação à vida. 
A dança ritualiza o natural e realiza, junto com a musicalidade dos instrumentos e da voz, o encantamento da vida. Dança-se no cotidiano, como também no extraordinário, o belo, aquilo que somos gratos/as: as doações de vida-nascimento, batismo (cerimônia do nome), aniversários diversos, saúde, alimento - as passagens que nos fazem crescer em espiritualidade, experiência e sabedoria- torna-se mulher/homem, iniciada/o, integrada/o, mais próxima/o dos segredos existenciais. A dança é também o que nos faz transcender a dor, a angústia, a injustiça, a humilhação, a tentativa de redução e de aniquilamento, lembrando-nos de quem somos, gerando a força espiritual que engrandece, potencializa e sacraliza (PETIT, 2015, p. 74-75).

Após esse momento de dança e exercícios, solicitamos que os/as copesquisadores escolhessem um local da sala onde se sentissem à vontade, pois, faríamos um relaxamento e uma viagem pelo corpo afrodescendente. Depois, o grupo foi dividido em 4 subgrupos que se separaram e se dirigiram para os materiais dispostos nos cantos da sala para a produção das metodologias como inclusão das culturas afrodescendentes na escola. Em seguida, ocorreram as apresentações, seguidas das discussões sobre a temática.

Para este artigo, selecionamos a produção de dois destes grupos para descrever o processo de criação das metodologias, as análises transversais das problematizações realizadas em torno da referida temática, categorizando os dados produzidos e registrados por meio de fotografias e filmagens. A partir daí, foram analisados os registros das experiências, de modo a ressaltar outras possiblidades de educar e que, ao serem produzidas, podem colocar em destaque o currículo inventivo na formação de graduandos/as de Pedagogia. Passemos, a seguir, para a descrição das metodologias em meio aos problemas que cada um ressalta em torno da afrodescendência na escola.

\section{Escritas de si I: metodologia do autorreconhecimento}

Nesta metodologia, o/a professor/a trabalha o autorreconhecimento dos discentes enquanto afrodescendentes, com o intuito de vencer o preconceito e lutar pelos seus direitos. Essa metodologia foi elaborada por meio de uma contação de história, destacando os problemas, outros modos de educar e os poderes adquiridos durante a sua construção.

A Metodologia do Autorreconhecimento revela um sentimento de Pertencimento Afro, que é situar-se dentro da ancestralidade africana, saber que se faz parte de uma linhagem que, para além de biológica, é de parentesco cultural. Em vista disso, não estamos mais nos referindo ao Africano como distante, na terceira pessoa, e sim, como parte do nosso convívio diário e é isso que traz sentimento de pertencimento, pois ser negro ou negra não é algo negativo, é sim, motivo de orgulho e de afirmação (PETIT, 2015). O dispositivo da 
Contação de histórias enquanto produto didático problematizou essas dimensões afrorreferenciadas.

O grupo denominou a história de Ubuntu que significa "Uma pessoa é uma pessoa através de outras pessoas" (NOGUEIRA, 2011, p. 147). Contaram e encenaram, assumindo os papéis dos seguintes personagens: a árvore, o homem e a menina. A produção foi realizada utilizando os seguintes materiais: retalhos, agulhas, lãs, tintas, cola, pincéis, papel peso 40, papéis e canetas coloridas. Como podemos visualizar a seguir:

\section{UBUNTU}

Bom Dia! Hoje nós teremos uma história diferente! A história de uma menina negra. Hoje vim contar a vocês uma história de quem somos nós. Certa vez, uma menina que se encontrava triste, no terreiro da sua escola, sob a sombra de uma árvore, que dizia os mais velhos, que era a morada dos ancestrais de uma antiga comunidade quilombola. A menina todos os dias corria para aquela árvore, pois, não compreendia o porquê os demais colegas viviam sorrindo do seu cabelo, e chorava toda a sua tristeza. Um dia, a menina dormiu a sombra da árvore, e sonhou com a árvore falando com ela. Ela [a árvore] perguntava: menina, por que choras? A menina respondeu: meus amigos riem dos meus cabelos! A árvore respondeu: minha filha, meus galhos e folhas importantes, foram presentes da mãe-natureza para coroar a majestade das plantas vindas de longe, de uma terra chamada África. Não chores, pois, você também é filha de um povo guerreiro e majestoso, e por isso, você foi coroada com os seus cabelos, para que nunca esqueçamos da nossa ancestralidade. A menina, a partir dai entendeu que a vontade da natureza de coroar o seu povo guerreiro, por isso, os seus cabelos, os brioches (GRUPO-PESQUISADOR).

A história Ubuntu transmite, especialmente, o marcador africano das/nas/sobre e com as formas de conviver/laços de solidariedade/relações comunitárias e cabelo afro (encaracolado/cacheado e crespo) (PETIT, 2015, p. 139). A história foi apresentada por meio da performance, envolvendo elementos como: a voz, a expressão facial, a expressividade, a gestualidade, o uso dramático da pausa e do ritmo, estimulando a interação entre os presentes, sendo que a roupa e os objetos utilizados também influenciaram ao enfatizar os marcadores e causar impactos, obtendo receptividade imediata e reações do "público" durante a oficina.

Em seguida, o grupo explicou como e onde aplicariam essa Metodologia, a qual ano poderia ser aplicada, bem como, os objetivos, os materiais utilizados e a avaliação a ser aplicada:

A forma que a gente pensa em aplicar esse trabalho na escola, como uma contação de história. Então, a gente decidiu que esse trabalho pode ser trabalhado na escola, principalmente nas disciplinas de história e geografia, nos anos iniciais do Ensino Fundamental. Os objetivos desse trabalho são: 
trabalhar a contação de histórias da cultura negra (africana), valorizar a cultura africana, pontuar a importância do cabelo afro para identidade negra. Os materiais que a gente poderia sugerir para uso em sala de aula são: livros que tragam a história da cultura africana, tinta, coleção (lápis de cor), pinceis, retalhos de tecidos, cola, papel, tesoura, entre outros. Pediremos para os alunos, em grupo, criar uma história e produzir um material como se fosse um cartaz a respeito da história contada. A avaliação da turma seria pela produção de cartazes sobre as histórias que seriam apresentadas na sala de aula (GRUPO-PESQUISADOR).

Para os discentes, é possível ao professor/a criar uma metodologia como essa, se este envolver imaginação e criatividade na invenção da história africana, contando-a na sala de aula, ou sugerir que os/as estudantes criem suas próprias histórias, por meios dos mais diversos gêneros textuais, como por exemplo: charges ou histórias em quadrinhos, com temáticas discutidas nas disciplinas estudadas, como um conteúdo transversal. Disseram, ainda, que a apresentação da história construída pode ser como um dispositivo de avaliação, como destacou o grupo. A temática seria sugerida tanto pelo/a professor/a após o levantamento da realidade que o cerca, quanto pelo estudante ao explicitar os seus desejos, tornando os processos de ensino e aprendizagem significativo, pois estaria aproximado dos seus interesses e dos problemas que os mobilizam.

Posteriormente, o grupo explicou o plano da metodologia, quais os procedimentos realizados. Primeiramente, o grupo se apropriou dos recursos como: o livro, objetos de cabelo que faziam relação com o tema e as experiências vividas por ele se e que possibilitaram a imaginação e a criatividade do grupo. Como podemos ver a seguir:

Para contar a história a gente usou inclusive os objetos que a gente trouxe e a viagem que a gente viveu durante o relaxamento. Os objetos que a gente trouxe foram o livro e os objetos de cabelo. A gente criou uma história com várias árvores, com um homem. O nome da história é UBUNTU. Na verdade, a gente começou através do mito que nos deram, ele já norteou essa questão de usar a própria cultura, a história dos antepassados para explicar porque o meu cabelo é assim. E como a gente foi revelando uns aos outros como tinha sido a experiência do relaxamento, a gente percebeu que dava para unir às três situações que contavam a mesma história (GRUPOPESQUISADOR).

Após a explicação sobre os procedimentos para a criação da metodologia, o grupo explicou o cartaz, recurso utilizado durante a contação da história:

Agora explicarei o nosso cartaz: essa é a menina com os briochezinhos de acordo com a história, foi importante porque casou com as nossas vivências durante o relaxamento. Vamos começar aqui: A criança, ela está no pátio da escola sofrendo dessa exclusão da sala de aula, ela corre para essa árvore, e eu queria que vocês identificassem que aqui existem várias 
árvores, mas há diferença entre elas; essas são de troncos verdes e as galhas são azuis, e essa é diferente, com o tronco azul e com os galhos encaracolados. O que a gente discutiu? Todas são árvores, mas uma se destaca, que é essa que a menina corre para lá. Aqui tem um personagem da minha vivência que foi esse homem colorido. Na verdade, esse homem colorido é a árvore-homem com vestes coloridas que é um professor que percebeu a tristeza da menina e escondeu-se atrás da árvore e começou a conversar com a garota como se fosse uma árvore. Por que que ele é a árvore? Porque simboliza a sabedoria. Quem é a sabedoria dentro da sala de aula? O professor, que está ali para ensinar e, ao mesmo tempo, ele aprende. Então, o professor notou que essa criança estava sofrendo com o que os coleguinhas faziam com ela e, também, que ela corria para aquela determinada árvore da escola. Qual foi a iniciativa dele? Ele não foi perguntar porque ela estava triste. Ele buscou um meio de interagir com ela e se posicionou atrás da árvore e no momento que ela estava dormindo, entrou no sonho da criança, falou com ela, que pensou ser a árvore. Só depois, quando ela compreende o porquê do cabelo dela, o porquê de ela ser assim, é que os dois adentram na escola com outro objeto a ser utilizado, o livro de história quilombola para mostrar para outras crianças que não existe preconceito, diferenciação, que todos são árvores e têm o mesmo valor, todos são iguais, todos precisam um dos outros. Essa foi a nossa compreensão (GRUPO-PESQUISADOR).

“Todos precisam uns dos outros", compreende o grupo! E diz ainda: "trabalho como este é possível desde que o professor não se isole, adotando a cultura do individualismo na escola". O trabalho em comum presente no sentido de Ubuntu:

uma maneira de viver, uma possibilidade de existir junto com outras pessoas de forma não egoísta, uma existência comunitária antirracista e policêntrica [...]Em linhas gerais, "ubu" indica tudo que está ao nosso redor, tudo que temos em comum. "Ntu" significa a parte essencial de tudo que existe, tudo que está sendo e se transformando (NOGUEIRA, 2011, p. 147-148).

Ubuntu é a perspectiva afrorreferenciada deslocada como atividade docente, não é uma tarefa isolada e nenhum/a professor/a deve se sentir oprimido por não conhecer determinado conjunto de saberes. A dificuldade na sala de aula é quando o professor não manifesta o seu pensamento, e não busca outras fontes, para saber o que o outro pensa. Por isso, é essencial que se possa ter um trabalho coletivo e compartilhado em todo o processo de ensino/aprendizagem: da preparação das aulas até a avaliação.

De acordo com Fullan (2000, p. 56), “esse isolamento dá para os/as professores uma espécie de proteção para colocar em prática o seu julgamento arbitrário [...] Todavia, também os/as impedem de obter um feedback significativo e claro acerca do valor e da eficácia daquilo que fazem". Desse modo, o autor supracitado destaca que a cultura do individualismo é criada na escola quando: 
[...] os professores receiam partilhar suas ideias e seus sucessos, por medo de serem percebidos como arautos de seus efeitos; quando os professores relutam em contar aos outros uma ideia nova por receio de que possam roubá-la ou assumir seu crédito (ou por acreditar que os outros devam passar por todo o processo de descoberta pelo qual passou); quando os professores, jovens ou mais velhos, têm medo de solicitar ajuda porque podem ser percebidos como pouco competentes; quando o professor utiliza o mesmo método ano após ano, mesmo que ele não traga resultado - todas essas tendências dão sustentação às paredes do individualismo. Elas limitam fundamentalmente o crescimento e o aperfeiçoamento, porque limitam o acesso a ideias e as práticas que poderiam oferecer maneiras mais eficientes de se fazer as coisas. Elas institucionalizam o individualismo (FULLAN, 2000, p. 58).

Entretanto, o grupo-pesquisador aponta o modo de operar a história Ubuntu como estratégia metodológica de construção coletiva tanto de conhecimento quanto de uma ética relacional entre eles, ressaltando a cultura Ubuntu como atividade docente e criação da metodologia em questão:

Se a gente tivesse ficado sentado, sem conversar, isso seria a dificuldade. Se eu não tivesse contado minha história não haveria um homem atrás de uma árvore, se ela não tivesse contado a história dela não haveria uma criança no meio do pátio, se ele não tivesse contado a história dele não haveria o professor e a criança dentro de uma escola (GRUPO-PESQUISADOR).

Então, a partir do momento que a gente se conheceu, a gente compartilhou experiências e saberes, essa dificuldade foi vencida, por quê? Porque a gente viu não a impossibilidade, mas várias possibilidades de se trabalhar essa história na sala de aula, pois as histórias se entrelaçaram. Ai vieram os relatos, veio a história disposta para a gente. Juntando tudo isso, formou essa arte! (GRUPO-PESQUISADOR).

Diante disso, o Ubuntu como compartilhar saberes e promoção de diálogos mostra-se fundamental para o sucesso da metodologia apresentada, demonstrando que "o resultado é muito diferente quando esta questão é abordada por equipes de professores na perspectiva do trabalho de (auto) formação" (CARVALHO; GIL-PÉREZ, 2011, p. 02). Nesse caso, o grupo aprendeu um com o outro muitos conhecimentos necessários para a formação docente na perspectiva afrorreferenciada.

\section{Escritas de si II: metodologia mistura: sabores e cheiros da afrodescendência na escola}

Esta metodologia nasce da elaboração da receita (hashtaq) \#angudaluta colocando os ingredientes, modo de preparo, tempo, porções destacando, na metodologia criada, os 
problemas, outros modos de educar e os poderes adquiridos durante a sua construção. Essa metodologia foi criada com os seguintes materiais: lantejoulas, botões, cola, massa de modelar, papel peso 40, giz de cera, papéis, canetas coloridas, para o registro da criação da receita para trabalhar a temática.

O grupo explicou qual era a metodologia que havia sido criada e quais os procedimentos realizados para a construção dessa metodologia na escola:

A gente vai fazer a receita, só que a gente escreveu uma metodologia, assim: Mistura: Sabores e Cheiros da Afrodescendência na escola. Porém, a nossa receita é hashtaq \#angudaluta. Inicialmente, provamos vários sabores e cheiros da cultura originalmente africana, relacionamos as suas principais características e os aspectos que o negro lida no seu dia a dia. Misturamos todos os ingredientes e juntamos com os poderes que emergem da luta pela igualdade e respeito (GRUPO-PESQUISADOR).

Como todo trabalho, é preciso definir o planejamento a ser realizado para a sua construção, e assim fez o grupo, quando definiu e traçou elementos para criar a metodologia em questão. Primeiramente, o grupo definiu que é preciso provar vários cheiros e sabores da cultura Africana disponibilizados pelas pesquisadoras. Em seguida, fazer a relação dos cheiros e sabores com as características e aspectos do tema abordado. Depois, juntar todos os ingredientes e criar a metodologia para ser trabalhada na escola.

Em continuidade, o grupo fez o seguinte comentário: “[...] essa metodologia mostrará para os alunos a cultura Afrodescendente, como o negro se percebe e é percebido na sociedade". Como podemos visualizar no relato a seguir, com a descrição da metodologia criada:

Utilizamos alimentos como: limão, banana, milho, batata-doce e temperos, ressaltando a contribuição e a importância da cultura Africana na construção da identidade do povo brasileiro. O ponto principal e base dessa metodologia é a mistura do povo brasileiro. O prato criado é o "Angu da luta". Modo de preparo: primeiro coloque meia cebola, depois meio limão e uma colher de chá de gengibre ralado, ou um pedacinho, certo? O que teremos? Teremos o azedo e o ardor da exclusão e do preconceito, né? Temos a goma, colocaremos um pouquinho da goma (uma mão-cheia), um pouquinho do floco de milho (uma mão-cheia), o sal (pitada), mas um pouco de floco de milho e teremos a liga que é a união de um povo e sua família. Para produzir a liga colocamos água e misturamos, pois, a água é vida, fonte de energia. Junte agora a batata-doce, a banana e terá força para enfrentar os desafios. Há não esqueça de temperar bem com: cominho, folhas de hortelã, manjericão e rúcula. Faça o melhor! Misture bem tudo! Teremos o que? Teremos isso! Misture tudo e encontrará na escola, problemas como preconceito e a exclusão, mas tenha força coragem e perseverança, autoconfiança e amor para enfrentar os desafios. Você é poderoso, você consegue! \#angudaluta! (GRUPO-PESQUISADOR). 
A receita \#angudaluta traz uma série de elementos que estão presentes em muitas escolas brasileiras, pois o grupo mostra que na escola o/a professor/a encontrará o problema do preconceito gerador da exclusão das infâncias, adolescências e juventudes afrodescendentes na sociedade. Entretanto, para vencer essa exclusão, o grupo destaca e apresenta elementos como: a união, que é fundamental para que uma escola funcione; a energia, que possibilita a força para o/a professor/a fazer o melhor e lutar; a autoconfiança, um elemento que dá coragem para ele/a colocar em prática o seu pensamento e o amor que o/a fortalece e o/a faz criar metodologias que tornem possível a existência viva de crianças e jovens afrodescendentes na escola.

União, energia, autoconfiança, amor são ingredientes de uma mistura que aquecem a luta contra as opressões e contra todos os obstáculos. Seria o aquecimento da razão pelos afetos, a dimensão sagrada, a dimensão feminina da vida e a sabedoria são expressões desta luta, processo através do qual as ideias e os conceitos continuam a despertar emoções motivadoras, emoções criativas e capacitadoras que reforçam a determinação de lutar e a disponibilidade para correr riscos. "Por isso, o aquecer da razão está associado ao aquecer da ética, sendo ambas pré-condições da indignação activa, o momento no qual o que tem vindo a ser tolerado se torna intolerável, tem de ser superado e pode ser superado." (SANTOS, 2018, p. 175).

Para o grupo, não foi fácil criar a metodologia Mistura: sabores e cheiros da afrodescendência na escola, pois, durante a experiência dos cheiros, o grupo se encontrava de olhos vendados. Então, sentiu dificuldades para identificar os cheiros e os sabores através do olfato e do paladar: "é muito difícil sair da própria pele, ou seja, da cultura própria, que se atribui uma posição hierarquicamente excelsa na pirâmide mundial dos sistemas de saber" para assumir o lugar do outro (SODRÉ, 2012, p. 49). Temos de nos aventurar, viver a experiência como um encontro, uma relação com algo que se prova, que se experimenta. Por isso, é habitando o mundo e seus riscos que se vai percebendo o tanto quanto em nós o mundo habita. Adad e Silva (2013). Como mostra o relato a seguir:

Sobre a experiência dos cheiros: quando você colocou para mim, eu tive uma confusão, a gente até colocou, a gente sentiu o cheiro de vinagre, mas o cheiro de vinagre era a goma. Para você ver que quando você fecha os olhos para as coisas, você não se permite conhecer, então, a gente tem que se permitir conhecer, você não necessariamente vai se envolver com elas, mas você pode conhecê-las, desvendá-las. Porque é muito fácil julgar, é muito fácil ter o preconceito, mas ninguém se permite conhecer, avaliar, se colocar no lugar do outro, na situação do outro. Não é que você vai assumir

RIAEE - Revista Ibero-Americana de Estudos em Educação, Araraquara, v. 16, n. 2, p. 682-702, abr./jun. 2021. e-ISSN: 1982-5587 
esse problema para você, não é que você vai assumir o problema do outro, mas é você se colocar naquela situação, será se eu queria aquilo para mim, será se eu queria aquilo para os meus filhos, será se eu quero aquilo para a minha família? Então, às vezes a gente se fecha no mundo da gente e não se permite conhecermos as coisas. É isso! (GRUPO-PESQUISADOR).

A partir desse relato, surgiu, em mim, os seguintes questionamentos: como criar outros modos de se permitir conhecer o outro? Como criar modos de levar para sala de aula o devir de se permitir experienciar as situações que são do outro? Como eu faço para vestir a pele do outro? Como o grupo mesmo destacou, não é fácil, mas é possível, é preciso apenas se despir dos julgamentos, de pré-concepções, deixar a acomodação de lado, e se permitir conhecer a si e ao outro, não é uma questão de assumir o problema do outro para si, colocar o outro em uma redoma e enfrentar tudo sozinho, mas de mostrar que eu não sou indiferente com o modo de viver do outro, pois é preciso rachar-se para conhecer o mundo do outro que habita em mim.

Desse modo, o grupo fez da dificuldade uma potência de mobilização pela luta, o que potencializou o corpo para agir ao possibilitar ao grupo criar em meio às situações improváveis. Assim, o grupo passou a ser uma flor de mandacaru que resiste durante o longo período de estiagem, pois foram as dificuldades que o fez pensar que os efeitos dos ingredientes estavam repletos de simbologias. Como mostra o comentário a seguir do grupopesquisador:

Como foi ela que elaborou o texto, a gente foi conversando e conseguimos a união dos ingredientes, mas não foi fácil, por isso, que a gente colocou o azedo, com o ardor, então, o que isso remete? O azedo da vida, da tristeza, as desilusões que as pessoas tiveram, os negros, de lutar contra esse sistema que persiste ainda. Então, a gente foi por parte trazendo a tristeza, as decepções, mas o negro persiste graças a Deus, ele vem lutando para conseguir o seu espaço. Tem na história mundial um primeiro presidente negro de uma nação dominante que isso representa muito para a nação mundial Afrodescendente (GRUPO-PESQUISADOR).

Trazer para dentro das salas de aulas práticas bem-sucedidas de afrodescendentes, histórias de sucesso, representa, para esses sujeitos e para a sociedade, uma formação para a cidadania, democracia e respeito, significa um compromisso com a vida de crianças, adolescentes e jovens Afrodescendentes. Segundo o grupo, por meio da metodologia Mistura: Sabores e Cheiros da Afrodescendência na escola, os/as Pedagogos/as serão capazes de lutar e aprender a lidar com os desafios encontrados durante a formação e durante a sua atuação na escola, uma vez que, os/as professores/as precisam ter:

a consciência e a autoconfiança, mas não deixar que esse sentimento se torne algo [...] que não permita que vocês vejam as coisas, que vocês não se 
sintam todo-poderoso, mas que vocês sejam capaz de quando as coisas não forem como você quer, persistir e não desistir, não pensar que vocês estão sozinhos na luta (GRUPO-PESQUISADOR).

Esta Metodologia potencializa o corpo do/a pedagogo/a lutar diante das dificuldades, e conscientiza, também, porque retira-lhe a vaidade e mostra-lhe a realidade. O/a professor/a aprende a enfrentar as adversidades, a persistir e, o mais importante, a perceber que não está sozinho/a:

\begin{abstract}
Viver é ir além de si mesmo, é sair do narcisismo, do etnocentrismo, pois, o que leva o homem a tornar-se obra de arte são as quedas são os erros e as perdas, porque nos obriga ser melhores e maiores do que somos. Diante dos saltos que tem que realizar e dos tombos que passa, o homem vai além de si mesmo, ultrapassa as dificuldades e se reinventa, potencializa o seu corpo, torna-se forte (ADAD; SILVA, 2013, p. 46).
\end{abstract}

Por sua vez, o grupo também traz dimensões opostas às da potência, ao fazer referência às fragilidades que vivem no processo da formação inicial, quando não se sente capaz de enfrentar desafios, apontando para as questões éticas como a responsabilidade, as implicações com a docência, como mostra o relato a seguir:

Às vezes a gente se diminui, a gente se torna pequeno, a gente se esconde com medo de lutar e a gente não pode levar isso para dentro da gente, nem para os nossos alunos. Porque nesses dois anos que eu estou aqui eu vejo que tem gente que fala: professor não é pai de aluna, ele não é responsável! Gente, fui aluna e eu tive professores que de alguma forma me bloquearam também, e a gente não pode permitir isso com os alunos. Nós, não podemos permitir viver isso. \#angudaluta! (GRUPO-PESQUISADOR).

A receita \#angudaluta é também a relação professor/a e estudante que se constitui como o coração da docência, pois não há vida, quando um está sem o outro. Professores/as e estudantes se criam, se recriam mutuamente, numa invenção de si que também é a reinvenção do outro e do mundo, revelando uma quebra de hierarquias e identidades fixas, construídas nas relações sociais (TEIXEIRA, 2007). A educação precisa desse sentimento de empatia pela vida!

[...] eu tenho escutado muito, nesses dois anos de universidade, que a gente pode se transformar, a gente não pode transformar o mundo, a gente pode transformar um pedaço dele, uma parte dele. Isso pode começar dentro da nossa família, na escola. A gente tem que começar a tomar para si a responsabilidade, que não é só do poder público, mas que é de todos nós. Que é essa luta contra o preconceito! (GRUPO-PESQUISADOR).

Essa metodologia possibilitou ao grupo problematizar as pequenas ações de inclusão no cotidiano da escola contra o racismo. A receita \#angudaluta empaticamente firma a vida na 
educação, misturando-se uns com os outros para pensar a educação afrodescendente e o valor que a cultura Afro tem na/para a vida de crianças, adolescentes e jovens afrodescendentes na escola, distanciando da indiferença, assumindo a corresponsabilidade nas práticas educativas.

\section{Considerações finais}

O pensamento do grupo-pesquisador trouxe duas dimensões heterogêneas e complexas desde a afrodescendência na escola, desdobrando-se em meio às escritas de si das metodologias inventivas produzidas nas oficinas com o Círculo de Cultura Sociopoética.

A primeira dimensão está relacionada aos problemas/dificuldades para pensar a inclusão dos afrodescentes, evidenciando a exclusão e o preconceito, por meio dos sentimentos das pessoas, que sofrem na escola de racismo, especialmente, crianças, adolescentes e jovens. O grupo, como firmação de outro modo de educar, traz a ética Ubuntu, que potencializa práticas educativas de pertencimento e valorização da perspectiva afrorreferenciada na escola. Ao utilizar a Metodologia do Autorreconhecimento, o/a docente provoca nos estudantes o empoderamento para enfrentar os racismos e os efeitos excludentes que atravessam suas vidas diariamente. Essa metodologia é desenvolvida através de uma contação de história que não necessita de muitos recursos, mas de muita imaginação e criatividade. Ubuntu transmite um sentimento de relação comunitária, superando-se a cultura do individualismo, ao adotar como estratégia o diálogo. Nesse caso, o grupo aprendeu um com o outro um grande número de conhecimentos necessários para a formação docente.

A outra dimensão está inserida na Metodologia Mistura: sabores e cheiros da afrodescendência na escola, a qual realça o/a professor/a em movimento de conscientizar e lidar com a realidade e com os desafios encontrados durante a formação e atuação na escola. Nesta dimensão, a prática educativa é conectada ao reconhecimento das relações recíprocas e empáticas entre professor/a e seus estudantes, realçando a responsabilidade, a importância da persistência e a percepção de que não se está sozinho/a nos espaços educativos. Esta metodologia é desenvolvida através de uma receita \#angudaluta que mostra ser possível enfrentar as dificuldades, o racismo quando o/a professor/a coloca em prática modos de sentir-pensar-agir que problematizem as dimensões afro, tornando possível a existência viva de crianças, adolescentes e jovens afrodescendentes na escola.

Diante de tudo o que foi citado anteriormente, ressaltamos a importância, nesta pesquisa, da escuta sensível dos problemas que mobilizavam os/as graduandos/as na formação inicial. Ouvi-los/as de modo intensivo, de corpo todo sobre a temática e os problemas que 
os/as mobilizam, foi considerá-los/as como capazes de formular questões significativas, de propor ações relevantes, de efetuar uma relação de diálogo consigo e com os outros nos espaços educativos longe das habituais, excludentes e hegemônicas formas de educar.

Assim, o presente artigo apresentou um estudo rizomático como pontes de linguagem e suas múltiplas conexões, afirmando a Vida na educação ao mostrar ser o emaranhamento de saberes possíveis ao romper os preconceitos e a exclusão por meio da criação e aplicação de metodologias sensíveis. Estratégias ou ações estas que se utilizam, inicialmente, das escritas de si, para que as histórias sejam valorizadas e os problemas sejam pinçados de suas próprias trajetórias afrodescendentes, tornando-os existências vivas, participativas, integradas e pertencentes à escola. Neste caso, a pesquisa mostra a potência da arte e do corpo na criação de possibilidades de romper com o que impede a Lei $\mathrm{n}^{\circ}$ 10.639-03 (BRASIL, 2003) ser discutida e efetivamente aplicada na escola.

\section{REFERÊNCIAS}

ADAD, S. J. H. C. Entre Lembrar e Esquecer: confetos sobre o corpo e violências, produzidos por jovens em pesquisas sociopoéticas. In: ADAD, S. J. H. C.; COSTA, H.M. S. (Org.) Entrelugares: tecidos socipoéticos em revista. Fortaleza: EdUECE, 2018. p. 175-195.

ADAD, S. J. H. C.; SILVA, P. G. R. Como se aprende com o corpo em movimento: narrativas de futuros pedagogos em formação na temática das juventudes. Linguagens, Educação e Sociedade, Teresina, ano 18, edição especial, p. 19-50. jul./ago. 2013.

BOAKARI, F. M. Mulheres Brasileiras Afrodescendentes de Sucesso: o discurso do fazer, fazendo diferenças. In: BOAKARI, F. M. Educação, gênero e afrodescendência: a dinâmica das lutas de mulheres na transformação social. Curitiba, PR: CRV, 2015. 152 p.

BRASIL. Lei n. 10.639/2003 de 9 de janeiro de 2003. Inclui a obrigatoriedade da temática História e Cultura Afro - Brasileira no currículo oficial da rede de ensino. Altera a Lei $\mathrm{n}^{\circ} 9$. 394, de 20 de dezembro de 1996. Brasília, DF, 10 jan.2003. Disponível em: http://www.planalto.gov.br/ccivil_03/leis/2003/110.639.htm. Acesso em: 08 abr. 2016.

BRASIL. Lei n. 12.711, de 29 de agosto de 2012. Dispõe sobre o ingresso nas universidades federais e nas instituições federais de ensino técnico de nível médio e dá outras providências. Brasília, DF, 30 ago. 2012. Disponível em: http://www.planalto.gov.br/ccivil_03/_ato20112014/2012/lei/112711.htm. Acesso em: 08 abr. 2016.

CARVALHO, A. M. P.; GIL-PÉREZ, D. Formação de professores de ciências: tendências e inovações. 10. ed. São Paulo: Cortez, 2011.

DELEUZE, G.; GUATTARI, F. Mil platôs: capitalismo e esquizofrenia. Rio de Janeiro: Ed. 34, 1997. v. 5.

FOUCAULT, M. A vida dos homens infames. In: O que é um autor? Lisboa: Vega, 1992.

RIAEE - Revista Ibero-Americana de Estudos em Educação, Araraquara, v. 16, n. 2, p. 682-702, abr./jun. 2021. e-ISSN: 1982-5587 
FULLAN, M. Escolas Totais. In: FULLAN, M.; HARGREAVES, A. (Org.). A escola como organização aprendente: buscando uma educação de qualidade. 2. ed. Porto Alegre: Artes Médicas Sul, 2000. Cap. 3. p. 56-81.

GAUTHIER, J.; ADAD, S. J. C. A sociopoética como abordagem de pesquisa e ensino decolonial, contracolonial e libertadora. Educazion e Aperta: Rivista di Pedagogia Critica, $\mathrm{n}$. 7, 22 Ago. 2020. Disponível em: https://educazioneaperta.it/archives/2861. Acesso em: 5 jan. 2021

KASTRUP, V.; BARROS, R. B. Movimentos- funções do dispositivo na prática da cartografia. In: PASSOS, E; KASTRUP, V; ESCÓSSIA, L. (Org.). Pistas do método da cartografia: pesquisa-intervenção e produção de subjetividade. Porto Alegre: Sulina, 2015. p. 76-91.

MACHADO, A. F. Saberes ancestrais femininos na filosofia africana: poéticas de encantamento para metodologias e currículos afrorreferenciados. Tese (Doutorado). Universidade Federal do Ceará. Programa de Pós-Graduação em Educação Brasileira. 2019. 268p. Disponível em: http://repositorio.ufc.br/bitstream/riufc/51976/5/2019_tese_afmachado.pdf Acesso em: 13 jan. 2021.

NOGUERA, R. Ubuntu como modo de existir: elementos gerais para uma ética afroperspectivista. Revista da ABPN, v. 3, n. 6, p. 147-150, nov. 2011- fev. 2012.

PETIT, S. H. Pretagogia: pertencimento, corpo-dança afroancestral e tradição oral contribuições do legado africano para a implementação da Lei n. 10.639/03. Fortaleza: EdUECE, 2015. 261 p.

PETIT, S. H. Recriando o Círculo de Cultura freireano pela Sociopoética: exemplos de uma trajetória de ensino em Educação Popular. In: COSTA, H. M. S.; ADAD, S. J. H. C. (Org.). Círculo de cultura sociopoética: diálogos com Paulo Freire, sempre! Fortaleza: EdUECE, 2019. p. 31-58.

PETIT, S. H; ALVES, M. K. F. Pretagogia, pertencimento afro e os marcadores das africanidades: conexões entre corpos e árvores ancestrais. In: MACHADO, A. F.; ALVES, M. K. F.; PETIT, S. H. (Org.). Memórias de Baobá II. Fortaleza: Imprece, 2015a. p. 125145.

SANTOS, B. S. O fim do império cognitivo. Portugal: Almedina, 2018. 533 p.

SILVA, M. S. B.; ADAD, S. J. H. C.; SILVA, K. S. Juventudes, comunidades periféricas, direitos humanos e educação. Research, Society and Development, v. 9, n. 10, p. e6599109155, 2020. DOI: https://doi.org/10.33448/rsd-v9i10.9155

SOARES, R. M. S. Técnicas diferenciadas: potencializando a construção coletiva do conhecimento no círculo de cultura. In: COSTA, H. M. S.; ADAD, S. J. H. C. (Org.). Círculo de cultura sociopoética: diálogos com Paulo Freire, sempre! Fortaleza: EdUECE, 2019. p. 59-80. 
SODRÉ, M. Reinventando a educação: diversidade, descolonização e redes. Petrópolis: Vozes, 2012.

TEIXEIRA, I. A. C. Da Condição docente: primeiras aproximações teóricas. Educ. Soc., Campinas, v. 99, p. 426-443, maio/ago. de 2007. DOI: https://doi.org/10.1590/S010173302007000200007

\section{Como referenciar este artigo}

ADAD, S. J. H. C.; SANTOS, T. T. M.; SILVA, M. S. B. Afrodescendência e metodologias inventivas para implementação da lei n. 10.639/03 na escola: a criação de jovens da pedagogia. Revista Ibero-Americana de Estudos em Educação, Araraquara, v. 16, n. 2, p. 682-702, abr./jun. 2021. e-ISSN: 1982-5587. DOI: https://doi.org/10.21723/riaee.v16i2.14663

Submetido em: 10/08/2020

Revisões requeridas em: 15/10/2020

Aprovado em: 26/12/2020

Publicado em: 01/02/2021 